\title{
Abscesos renales
}

Kidney abscesses

\author{
Verónica Argüello Ramírez, * Karen Dalton Ceballos, * \\ David Hernández Villeda,* María de Guadalupe Gómez Pérez ${ }^{\ddagger}$
}

El absceso renal es una complicación poco frecuente, pero grave dentro de las infecciones del tracto urinario (ITU), presentaba una mortalidad de 39-50\% en la década de los años 60 y 70 del siglo XX. Actualmente, gracias a la disponibilidad del diagnóstico por imágenes, además de un manejo agresivo, la letalidad se ha reducido a $6 \%$. Sin embargo, el diagnóstico sigue siendo difícil, ya que los pacientes presentan una sintomatología difusa y poco específica, siendo 10\% de ellos oligosintomáticos. ${ }^{1}$

La vía principal de infección es la ascendente (75\%), siendo los microorganismos aislados más frecuentes la $E$. coli $(26 \%)$, Klebsiella pneumoniae (22\%), Staphylococcus aureus (18\%), a pesar de que sólo $50 \%$ de los urocultivos resulta positivo. ${ }^{1,2,3}$ Entre los factores de riesgo están: la presencia de litiasis renal que bloquea el flujo urinario y sirve de reservorio para la infección, anormalidades del tracto urinario, estasis urinaria, cirugía urológica, biopsia renal, embarazo, drogadictos por la vía endovenosa, vejiga neurógena, trauma renal, hemodiálisis y diabetes mellitus.
Femenino de 34 años originaria del Estado de México habita casa propia, cuenta con todos los servicios domiciliarios y extradomiciliarios, zoonosis negada, baño y cambio de ropa todos los días, alimentación adecuada en cantidad y calidad.

Inicia padecimiento actual en el mes de febrero de 2019 caracterizado por fiebre de predominio nocturno asociada con dolor lumbar, náuseas y vómitos.

A la exploración física Giordano bilateral positivo, se realiza estudio de laboratorio, el cual reporta leucocitosis así como resonancia magnética de abdomen en la que se observan imágenes ovoideas de bordes irregulares hipointensas en ponderación T1 e hiperintensas en ponderación T2, las cuales presentan realce periférico al paso del medio de contraste localizadas en polo inferior derecho con dimensiones aproximadas de $2.7 \times 2.3 \mathrm{~cm}$ y en tercio medio izquierdo con dimensiones de $2.1 \times 2.8 \mathrm{~cm}$ en sus ejes mayores, sistemas colectores y pelvicillas renales sin evidencia de alteraciones en relación a abscesos renales (Figuras 1A, 1B y 2).
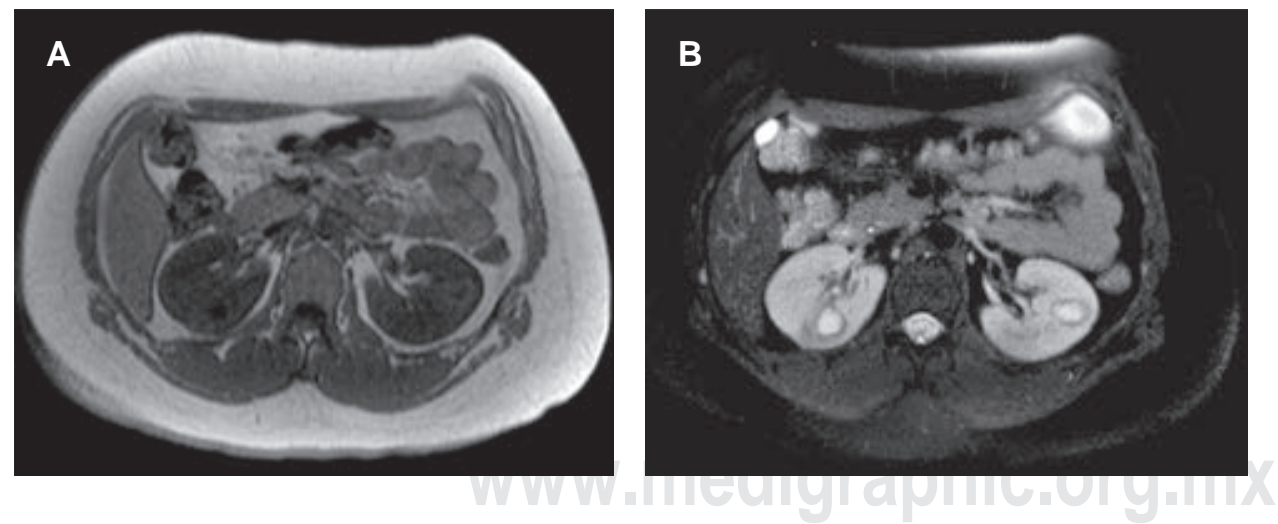

Figura 1:

Resonancia magnética plano axial en secuencias ponderadas en T1 y T2 saturación grasa donde se observan lesiones a nivel de parénquima renal, ovoideas, circunscritas, hipointensas en T1 e hiperintensas en T2.

\footnotetext{
* Médico Residente del Curso de Alta Especialidad en Resonancia Magnética cuerpo completo, Facultad de Medicina de la UNAM.

‡ Jefe del Servicio de Resonancia Magnética.
}

Hospital Ángeles Pedregal. Ciudad de México, México.
Correspondencia:

Dra. Verónica Argüello Ramírez

Correo electrónico: ramirez961202@yahoo.com.mx

Aceptado: 08-08-2019.

www.medigraphic.com/actamedica 


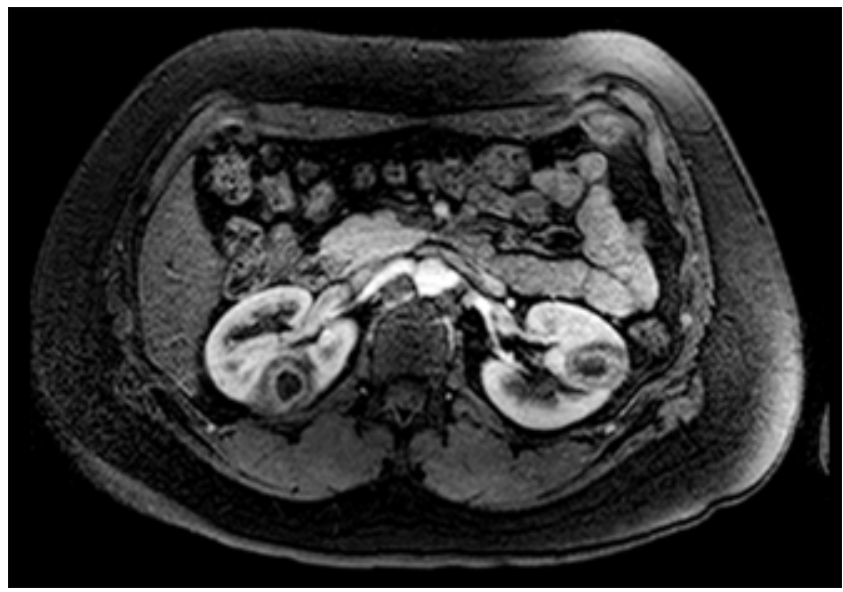

Figura 2: Resonancia magnética en plano axial contrastada donde se aprecia importante realce al paso del medio de contraste de lesiones renales parenquimatosas.

\section{CONCLUSIÓN}

Las infecciones del tracto urinario constituyen una de las principales enfermedades hospitalarias de la práctica clínica diaria. Las pruebas de imagen se reservan para aquellos pacientes que no responden al tratamiento antibiótico, pacientes con comorbilidades o con presencia de síntomas severos o atípicos.

Por lo que es importante llevar acabo un diagnóstico temprano que permita un tratamiento adecuado y de esta manera evitar complicaciones. En caso de no poder determinar éste a través de métodos de imagen iniciales como ecografía y tomografía en pacientes con presentaciones clínicas atípicas, una opción es realizar resonancia magnética en diferentes secuencias que nos ayuden a determinar mayor precisión diagnóstica.

\section{REFERENCIAS}

1. Fullá OJ, Storme CO, Fica CA, Varas PM, Flores MJ, Marchant GF et al. Abscesos renales y peri-renales: análisis de 44 casos. Rev Chil Infectol. 2009; 26 (5): 445-451.

2. Maldonado-Alcaraz E, Ixquiac Pineda G, López-Sámano V, Serrano Brambila E. Absceso perirrenal: factores asociados a su desarrollo y mortalidad. Arch Esp Urol. 2008; 61 (1): 7-12.

3. Capitán Manjón C, Tejido Sánchez A, Piedra Lara JD, Martínez Silva V, Cruceyra Betriu G, Rosino Sánchez A et al. Retroperitoneal abscesses-analysis of a series of 66 cases. Scand J Urol Nephrol. 2003; 37 (2): 139-144. 